\title{
Microfilaments in the cells of the human trabecular meshwork
}

\author{
I. GRIERSON AND A. H. S. RAHI \\ From the Department of Pathology, Institute of Ophthalmology, London
}

SUMMARY In this present study the results are presented of a combined ultrastructural and immunofluorescent investigation of 'smooth muscle' elements within the cytoplasm of human trabecular meshwork cells. The cytoplasm of human meshwork cells both in vivo and in vitro is replete with $10 \mathrm{~nm}$ intermediate filaments and also contains smaller $6 \mathrm{~nm}$ filaments which are particularly prominent in the cell processes. By immunofluorescence using sera rich in antibodies to contractile proteins, particularly actin, cultured meshwork cells showed strong cytoplasmic fluorescence. On occasion the cytoplasmic fluorescence was diffuse, but more often recognisable bundles (stress fibres) or a loose fibrillar framework was found. The possible role of structural and contractile cellular proteins in trabecular function was discussed.

It has been shown that trabecular meshwork cells are extremely pliable, and in experimentally induced acute increase of intraocular pressure (Grierson and Lee, 1975; Kayes, 1975; Svedbergh, 1976) or after the application of topical pilocarpine (Grierson et al., 1978) these cells are capable of pronounced attenuation without loss of cell-to-cell contact. Grierson and Lee (1975) suggested that cytoskeletal elements and, in particular, the cytoplasmic microfilaments could be expected to have a key role in cellular pliability, and thus they will have an important function in the maintenance of tissue integrity.

Further, it is known that the structural cytoplasmic proteins of many non-muscle cells, in addition to having cytoskeletal functions, can play a part in cellular mobility and contraction (Pollard and Weihing, 1974). If contractile proteins are a component of the cytoplasm of trabecular meshwork cells, it could be expected that filament-dependent cellular contraction may have an influence on outflow dynamics (Inomata et al., 1972). Indeed it has been shown that the intraocular infusion of cytochalasin B, which disrupts contractile cytoplasmic microfilament systems, produces a marked increase in the facility of aqueous outflow (Kaughman and Barany, 1977).

Clearly structural and contractile cytoplasmic proteins may be of some importance to trabecular

Address for reprints: Dr I. Grierson, Department of Pathology, Institute of Ophthalmology, Judd Street, London WC1H 9QS function. Therefore the present investigation was conducted to determine the nature and distribution of cytoplasmic microfilaments in the cells of the normal human trabecular meshwork, and an attempt was made to demonstrate the presence of contractile protein antigens within cultured human trabecular meshwork cells by means of an immunofluorescent technique.

\section{Materials and methods}

NORMAL TISSUE

Normal angular tissue for electron microscopy was obtained from 11 human eyes enucleated in treatment of malignant melanoma of the posterior globe. The patients' ages varied between 46 and 76 years. The eyes showed no clinical evidence of abnormalities in the anterior segment. After enucleation they were immersed in 3\% phosphate buffered glutaraldehyde and opened by equatorial section; the lenses were removed, and slices of limbal tissue were taken for further processing. After a wash in phosphate buffer the limbal segments were post-fixed in phosphate buffered osmium tetroxide, rewashed in buffer, dehydrated through graded alcohols, cleared with propylene oxide, and embedded in Araldite.

\section{TISSUE CULTURE}

The globes for tissue culture were provided by the eye bank and were used from 6 to 48 hours post mortem. The anterior segment of each eye was divided into quadrants, and the iris and ciliary body were removed under the dissecting microscope. Two 
parallel cuts were made in the trabecular region, and the strip of drainage tissue was carefully removed with minimal handling. The trabecular meshes were transferred to the cover glass of a tissue culture chamber and embedded in an embryonic plasma clot. The chamber was then sealed and filled with a tissue culture medium. For further details see Tripathi et al. (1973).

Outgrowths from the explant spread over the surface of the coverslip, and after 6 weeks to 3 months the primary culture was sufficiently well established for either electron microscopy or immunofluorescent studies. Preparation of the trabecular meshwork cells on the coverslips for electron microscopy was by the technique described by Tripathi et al. (1973) and Rahi and Ashton (1978).

\section{IMMUNOFLUORESCENT STUDIES}

For this part of the investigation the coverslips containing monolayers of cultured trabecular meshwork cells were washed in isotonic saline and fixed in acetone.

Blood from patients with chronic uveitis or intraocular melanoma containing high titres (greater than $1 / 160)$ of antibodies to 'smooth muscle' proteins, particularly actin (Rahi et al., 1976; Rahi and Ashton, 1978) were used as the source of antiserum to localised contractile cytoplasmic proteins. The reactivity and specificity of the sera were judged by examination of frozen sections from composite blocks of rat liver, kidney, skeletal muscle, stomach, and salivary gland which had been treated with the sera (Trenchev and Holborow, 1976).

After treatment with the appropriate sera the method outlined by Rahi et al. (1976) and Rahi and
Ashton (1978) using fluorescein labelled antihuman immunoglobulins was adopted. A Zeiss epifluorescence microscope equipped with a fluorescein isothiocyanate interference filter was used for routine examination of the tissues.

\section{Results}

ULTRASTRUCTURE

The trabecular meshwork cells of the normal human outflow apparatus contained 2 types of cytoplasmic microfilaments of indeterminate length but of different diameters. The larger filaments measured $10 \mathrm{~nm}$ in diameter and were most abundant in the main cell body and in the perinuclear zone (Fig. 1). The $10 \mathrm{~nm}$ filaments were formed into either sporadically distributed bundles (Fig. 2) or, more commonly, a subcortical network, so that in any one section the filaments were cut both in cross section and in longitudinal section (Fig. 1). These filaments did not make contact with the plasma membrane but did come into close association with the limiting membranes of some cytoplasmic organelles (Fig. 1).

The finer, more delicate filaments measured between 5 and $6 \mathrm{~nm}$ in diameter and were found in loose aggregates throughout the cell cytoplasm from the perinuclear zone to the cell periphery. The fine filaments were particularly prevalent in the cell processes, where they were orientated so that they formed an array which ran parallel with the long axis of the cytoplasmic projection (Fig. 3). Unlike the larger filaments the fine filaments came into close proximity with the plasma membrane (Figs. 3 and 4).

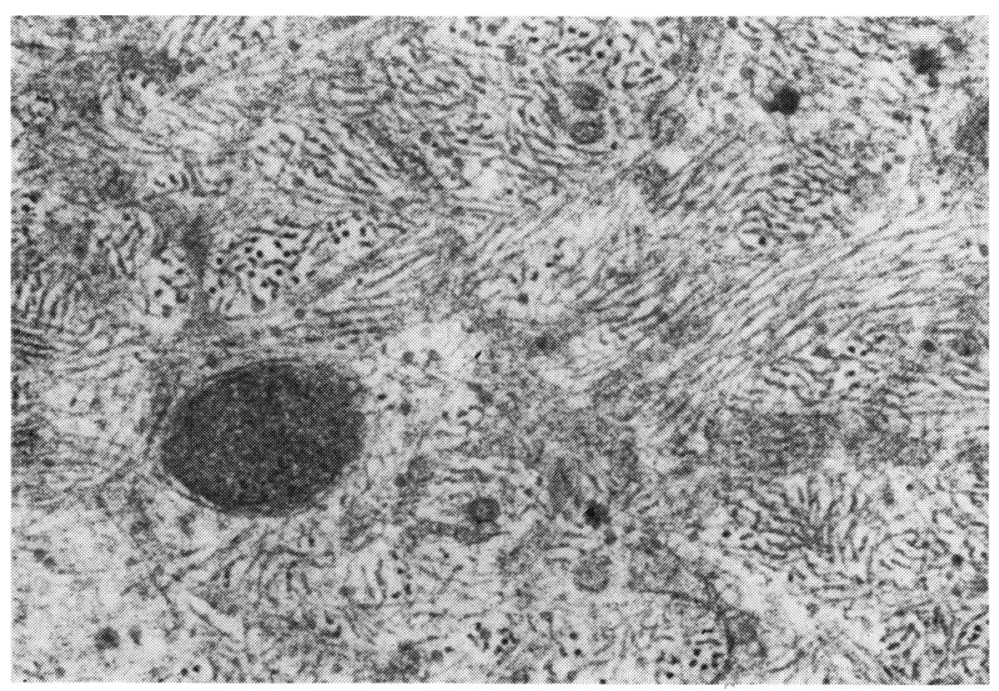

Fig. 1 Electron micrograph showing $10 \mathrm{~nm}$ microfilaments in the cytoplasm of a trabecular meshwork cell. The microfilaments form a network and can be seen both in cross and in longitudinal section $(\times 60000)$ 
Fig. 2 Electron micrograph showing a bundle of $10 \mathrm{~nm}$ microfilaments in the cytoplasm of a trabecular meshwork cell $(\times 50000)$
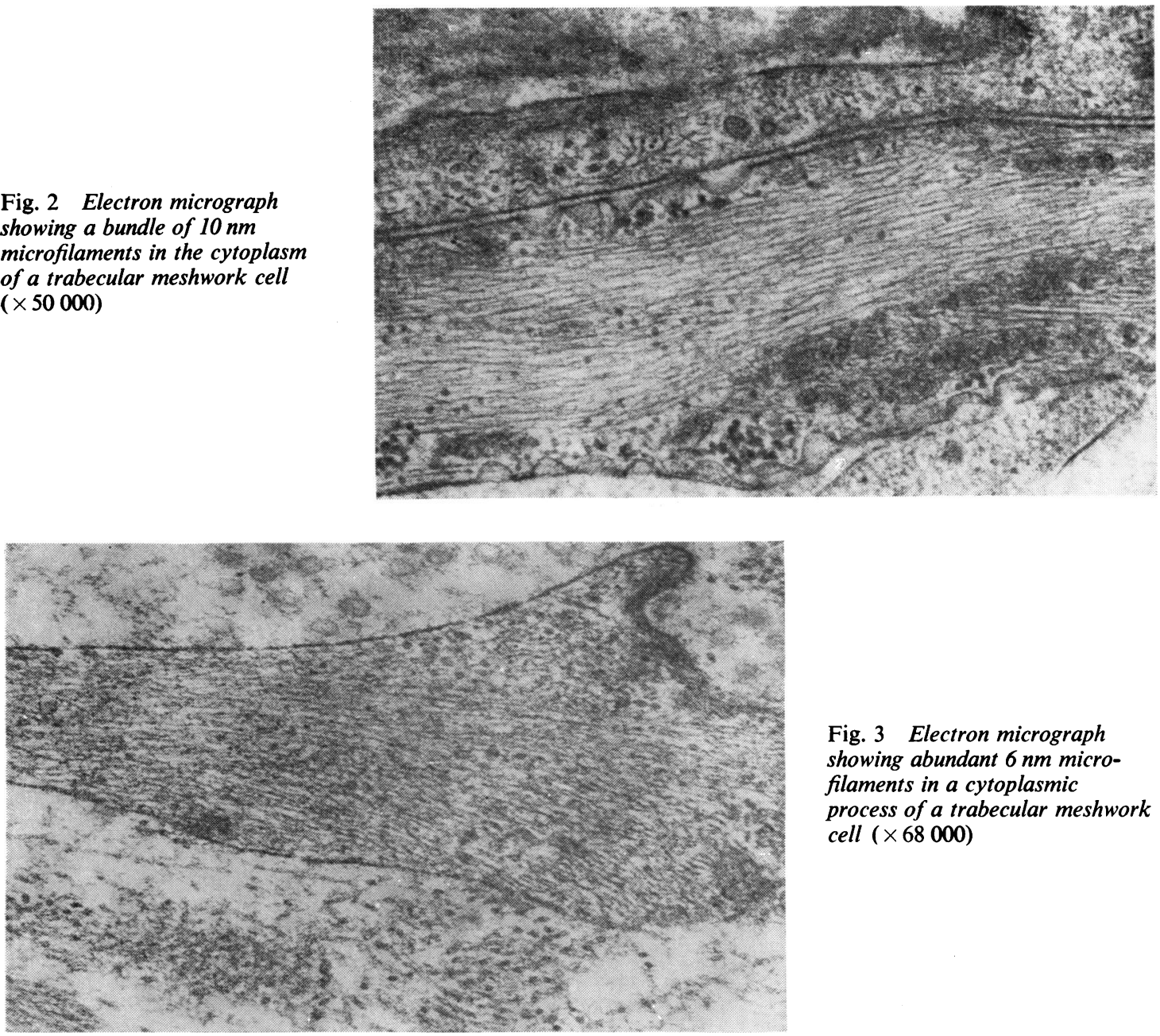

Fig. 3 Electron micrograph showing abundant $6 \mathrm{~nm}$ microfilaments in a cytoplasmic process of a trabecular meshwork cell $(\times 68000)$

Fig. 4 Electron micrograph of trabecular meshwork cells, trabecular cores indicated $(\mathrm{T})$. In one cell $10 \mathrm{~nm}$ intermediate microfilaments predominate (I), whereas in the others $6 \mathrm{~nm}$ microfilaments can be seen (arrows) $(\times 40000)$

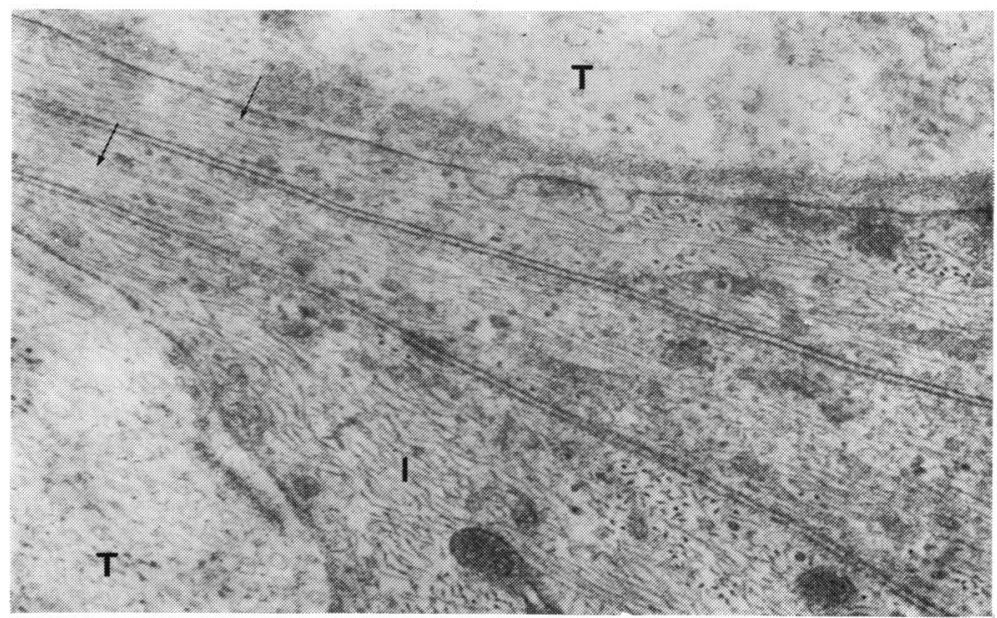


Studies of the fine structure of cultured trabecular meshwork cells revealed the presence of both types of cytoplasmic micro.ilament previously described.
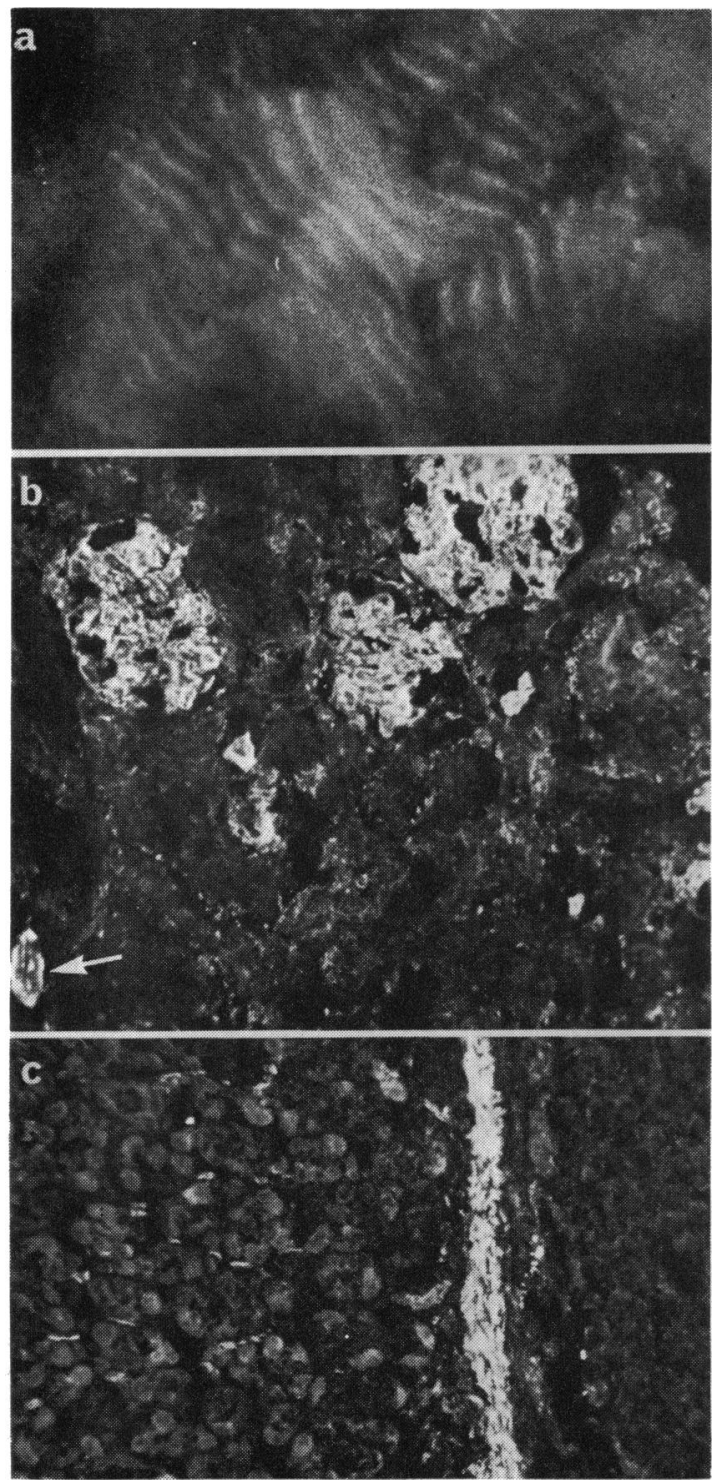

Fig. 5 Indirect immunofluorescence tests on cryostat sections of rat tissues. (a) The anti-actin antibody in the sera reacts at the 'I' band to produce distinctive fuorescence in skeletal muscle $(\times 1100)$. (b) A section through the wall of the stomach shows bright fluorescence at the muscularis mucosa and also in the muscle fibres between the gastric glands $(\times 190)$. (c) In a section of kidney the sera have reacted with contractile proteins of cells in the glomeruli and in the wall of an artery (arrow) $(\times 190)$
IMMUNOFLUORESCENT STUDIES

From the multiple blocks the skeletal muscle showed specific fluorescence for the 'I' bands (Fig. 5a). The muscle fibres between gastric glands were strongly fluorescent (Fig. $5 b$ ), as were the glomeruli and peritubular tissue of the kidney (Fig. 5c). In addition hepatocytes showed a polygonal staining pattern. On the basis of these findings it was evident that the sera used reacted strongly with cells which are known to have an abundance of 'smooth

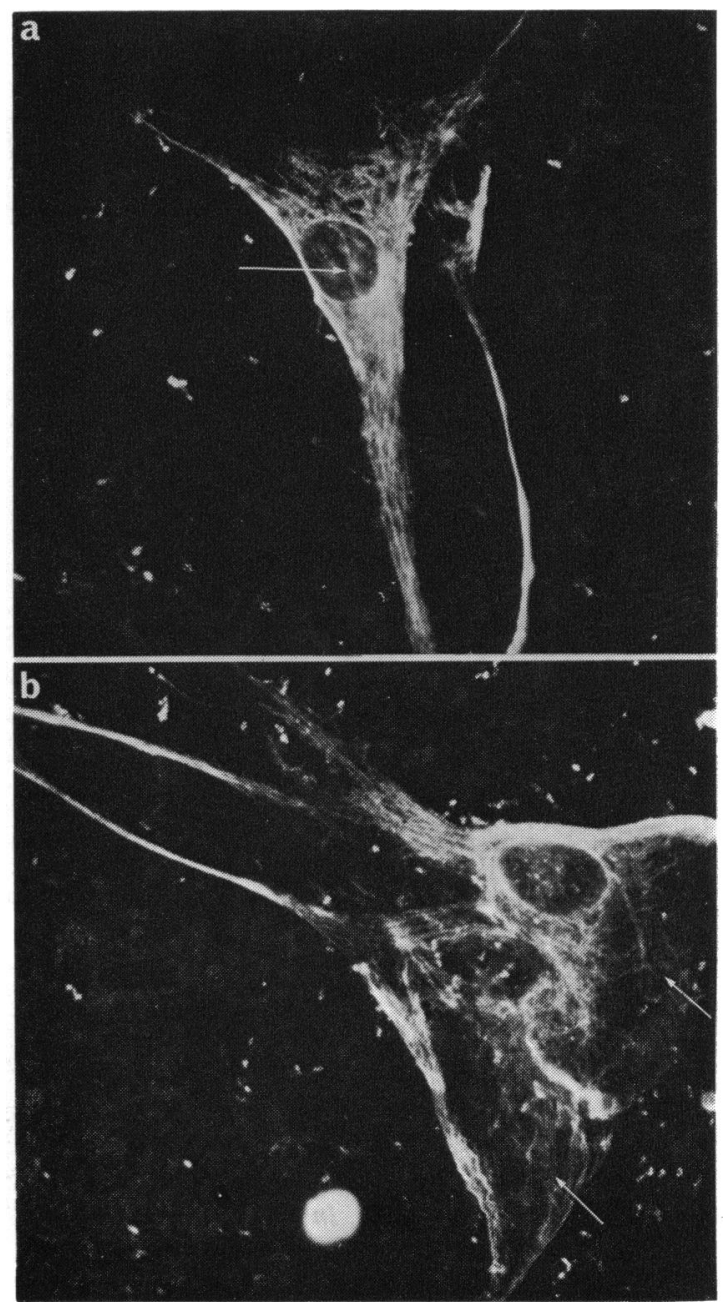

Fig. 6 Acetone fixed cultured trabecular meshwork cells tested by the indirect immunofluorescence with anti'smooth muscle' sera. (a) Strong cytoplasmic fluorescence in a meshwork cell. Note the unstained cell nucleus (arrow) $(\times 520)$. (b) Two meshwork cells in which there is strong fluorescence in the long extended cell processes. A fluorescence-positive network can be seen in the main cell body (arrow) $(\times 520)$ 
muscle' proteins and to be particularly rich in actin.

When cultured trabecular meshwork cells were treated with the sera, there was a strongly positive cytoplasmic fluorescence. Cytoplasmic fluorescence was particularly prominent in the cell processes (Fig. 6), at the cell margin, and as a perinuclear halo. At higher magnification recognisable fibres or bundles were found both in the main cell body (Fig. 7a) and in the cellular processes (Fig. 7b). The bundles were orientated so that they ran parallel with the long axis of the cell, and similar bundles have been described in other cell types, where they
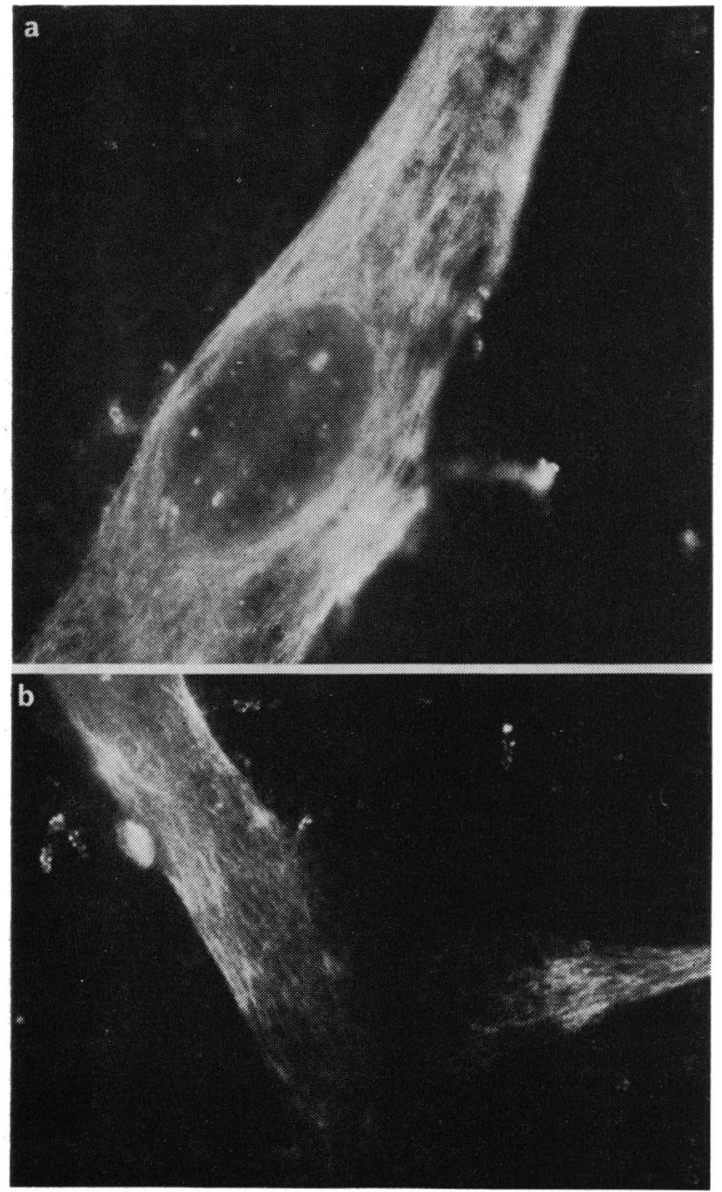

Fig. 7 (a) Part of a trabecular meshwork cell fixed with acetone and tested by indirect immunofluorescence using serum which contains anti-'smooth muscle' antibody. Subcortical bundles of actin-containing filaments can be seen ( $\times 935)$. (b) A trabecular meshwork cell process from a culture which was fixed in acetone and treated with serum containing anti-'smooth muscle' antibodies. Bundles or sheaths of contractile protein are evident $(\times 765)$ have been called 'stress fibres' (Wessells et al., 1971). Stress fibres were not found in all the cells examined; in some there was only diffuse cytoplasmic staining, whereas in others a loose fibrillar framework could be identified (Fig. 6).

\section{Discussion}

The cytoplasm of human trabecular meshwork cells is rich in 6 and $10 \mathrm{~nm}$ microfilaments. The $6 \mathrm{~nm}$ microfilaments were most numerous at the cell periphery, round the cell nucleus, and within cytoplasmic processes. It was therefore of interest to note that the forementioned sites showed, in most meshwork cells, the strongest fluorescence after exposure to sera rich in antibodies to actin and other contractile proteins.

Recently Ringvold (1978) was able to identify 4.5 to $6.5 \mathrm{~nm}$ cytoplasmic filaments in the trabecular meshwork cells of the vervet monkey. He exposed glycerinated segments of trabecular meshwork to myosin subfragment (S-1), which forms characteristic 'arrowhead' complexes with actin containing microfilaments. Ringvold found that 'arrowhead' complexes were prevalent on the 4.5 to $6.5 \mathrm{~nm}$ diameter filaments and suggested that they. were therefore actin filaments. Actin in conjunction with myosin is involved in cellular contraction and motility but also plays a part in other biological functions such as phagocytosis, pinocytosis, and cell adhesion (Allison et al., 1971; Malawista et al., 1971; Wessells et al., 1971; Pollack and Rifkin, 1975; Tilney, 1975).

However, the predominant cytoskeletal component of human trabecular meshwork cells was shown to be $10 \mathrm{~nm}$ diameter filaments. These so-called intermediate filaments are of uncertain chemical identity (Lansing-Taylor, 1975). Only 1 component protein within these structures has been described so far and has been called alternatively desmin or skeletin (Kurki et al., 1977). It has been suggested that typically they do not have an actin component (Ishikawa et al., 1969) and that they have a structural rather than a contractile role. On the other hand the distribution of intermediate filaments is altered at the onset of locomotion by leukaemia cells (Felix and Strauli, 1976), and $10 \mathrm{~nm}$ filaments in pigment epithelial cells of the retina do contain actin (Burnside, 1976), though this may be an exceptional case. Also $10 \mathrm{~nm}$ intermediate filaments are involved in axoplasmic transport in nerve cells (Felix and Strauli, 1976) and have been implicated in the intracellular transport of cytoplasmic organelles in fibroblasts (Goldman and Follett, 1969).

The structural and contractile proteins within trabecular meshwork cells may well be of some 
importance to trabecular function, since trabecular cell pliability and contraction may influence the width of intertrabecular spaces and hence affect the rate of aqueous outflow (Kaughman, 1977). However, it is also known that trabecular meshwork cells are latent phagocytes, and in various forms of secondary open-angle glaucoma the native cells of the drainage system engulf considerable quantities of debris (Grierson and Lee, 1973; Van Buskirk and Leure-Dupree, 1978). Recently the suggestion has been put forward that primary open-angle glaucoma may arise as a result of an inability of meshwork cells to phagocytose and get rid of the debris which may accumulate in the outflow system of the older eye (Bill, 1975). If this interesting hypothesis is to be tested, clearly it would be worthwhile to embark on further studies of the filament systems within these cells, which, as has been stated previously, are known to have a key role in the phagocytic process.

Although it has been established in the study reported here that contractile proteins are present in human trabecular meshwork cells, more detailed investigations need to be performed to determine which smooth muscle contractile proteins apart from actin are present in these cells and what role they play in cell contraction, anchorage, and phagocytosis in the normal and diseased outflow system.

We are grateful to Professor N. Ashton for helpful criticism; Mr J. Prasad and Miss E. Robins for technical assistance; and Mrs A. Wood for secretarial help.

\section{References}

Allison, A. C., Davies, P., and de Petris, S. (1971). Role of contractile microfilaments in macrophage movement and endocytosis. Nature, 232, 153-155.

Bill, A. (1975). The drainage of aqueous humor. Investigative Ophthalmology, 14, 1-3.

Burnside, M. B. (1976). Possible roles of microtubules and actin filaments in retinal pigmented epithelium. Experimental Eye Research, 23, 257-275.

Felix, H., and Strauli, P. (1976). Different distribution pattern of $100-\AA$ filaments in resting and locomotive leukaemia cells. Nature, 261, 604-605.

Goldman, R. D., and Follet, E. A. C. (1969). The structure of the major cell processes of isolated BHK21 fibroblasts. Experimental Cell Research, 57, 263-276.

Grierson, I., and Lee, W. R. (1973). Erythrocyte phagocytosis in the human trabecular meshwork. British Journal of Ophthalmology, 57, 400-415.

Grierson, I., and Lee, W. R. (1975). The fine structure of the trabecular meshwork at graded levels of intraocular pressure. (1) Pressure effects within the near physiological range. Experimental Eye Research, 20, 505-522.

Grierson, I., Lee, W. R., and Abraham, S. (1978). Effects of pilocarpine on the morphology of the human outflow apparatus. British Journal of Ophthalmology, 62, 302-313.

Inomata, H., Bill, A., and Smelser, G. K. (1972). Aqueous humor pathways through the trabecular meshwork and into Schlemm's canal in the cynomolgus monkey (Macaca irus). An electron microscopic study. American Journal of Ophthalmology, 73, 760-789.

Ishikawa, H., Brischoff, R., and Holtzer, H. (1969). Formation of arrowhead complexes with heavy meromyosin in a variety of cell types. Journal of Cell Biology, 43, 312-328.

Kaughman, P. L., and Barany, E. H. (1977). Cytochalasin B reversibly increases outflow facility in the eye of the cynomolgus monkey. Investigative Ophthalmology, 16, 47-53.

Kaughman, P. L. (1977). Drugs and the trabecular meshwork. Investigative Ophthalmology, 16, 475-477.

Kayes, J. (1975). Pressure gradient changes in the trabecular meshwork of monkeys. American Journal of Ophthalmology, 79, 549.

Kurki, P., Linder, E., Virtanen, I., and Stowman, S. (1977). Human smooth muscle autoantibodies reacting with intermediate (100 $\AA)$ filaments. Nature, 268, 240-241.

Lansing-Taylor, D. (1975). Dynamics of cytoplasmic structure and contractility. In Molecules and Cell Movement. Edited by S. Inoue and R. E. Stephens. Raven Press: New York.

Malawista, S. E., Gee, J. B. L., and Bensch, K. G. (1971). Cytochalasin B reversibly inhibits phagocytosis. Functional, metabolic, and ultrastructural effects in human blood leukocytes and rabbit alveolar macrophages. Yale Journal of Biology and Medicine, 44, 286-300.

Pollack, R., and Rifkin, D. (1975). Actin-containing cable within anchorage-dependent rat embryo cells are dissociated by plasma and trypsin. Cell, 6, 495-506.

Pollard, T. D., and Weihing, R. R. (1974). Actin and myosin and cell movements. Critical Reviews in Biochemistry, 2, $1-65$.

Rahi, A., and Ashton, N. (1978). Contractile proteins in retinal endothelium and other non-muscle tissues of the eye. British Journal of Ophthalmology, 62, 627-643.

Rahi, A. H. S., Holborow, E. J., Perkins, E. S., Gungen, Y. Y., and Dinning, W. J. (1976). Immunological investigations in uveitis. Transactions of the Ophthalmological Societies of the United Kingdom, 96, 113-122.

Ringvold, A. (1978). Actin filaments in trabecular endothelial cells in eyes of the vervet monkey. Acta Ophthalmologica, 56, 217-225.

Svedbergh, B. (1976). Aspects of the aqueous humor drainage. Functional ultrastructure of Schlemm's canal, the trabecular meshwork and the corneal endothelium at different intraocular pressure. Acta Universitatis Uppsaliensis, 256, 1-71.

Tilney, L. G. (1975). Actin: Its association with membranes and the regulation of its polymerization. In Molecules and Cell Movement. Edited by S. Inoue and R. E. Stephens. Raven Press: New York.

Trenchev, P., and Holborow, E. J. (1976). The specificity of anti-actin serum. Immunology, 16, 125-136.

Tripathi, B., Ashton, N., and Knight, G. (1973). Effect of oxygen on the developing retinal vessels of the rabbit. III. Mode of growth of rabbit retinal vessels in tissue culture. Experimental Eye Research, 15, 321-351.

Van Buskirk, E. M., and Leure-Dupree, A. E. (1978). Pathophysiology and electron microscopy of melanomalytic glaucoma. American Journal of Ophthalmology, 85, 160-166.

Wessells, N. K., Spooner, B. S., Ash, J. F., Bradley, M. O., Luduena, M. A., Taylor, E. C., Wrenn, J. T., and Yamada, K. M. (1971). Microfilaments in cellular and developmental processes. Science, 171, 135-143. 